\title{
Relevância dos conhecimentos, habilidades e métodos instrucionais na perspectiva de estudantes e profissionais da área contábil: estudo comparativo internacional
}

\section{Relevance of knowledge, skills and instructional methods from} the view point of accounting students and professionals: an international comparative study

Ernani Ott

Professor Titular da Universidade do Vale do Rio dos Sinos.

E-mail: ernani@unisinos.br

Jacqueline Veneroso Alves da Cunha

Professor Adjunto da Universidade Federal de Minas Gerais.

E-mail: jvac@face.ufmg.br

Edgard Bruno Cornacchione Júnior

Professor Titular da Faculdade de Economia, Administração e Contabilidade da Universidade de São Paulo do Departamento de Contabilidade e Atuária

E-mail: edgardbc@usp.br

Márcia Martins Mendes De Luca

Professor Adjunto da Universidade Federal do Ceará.

E-mail: marcia@mmconsultoria.srv.br

Recebido em 18.07.2011 - Aceito em 13.10.2011 - $3^{a}$. versão aceita em 29.11.2011

\section{RESUMO}

Com o incentivo dos estudos de Albrecht e Sack (2000), Francisco e Kelly (2002) e com base na Taxonomia de Bloom (1956), o objetivo deste trabalho consiste em comparar a percepção de estudantes de cursos de Ciências Contábeis em Instituições de Ensino Superior (IES) brasileiras e profissionais da Contabilidade no Brasil quanto aos conhecimentos, habilidades e métodos de ensino-aprendizagem considerados como mais importantes para a atuação do contador no mercado de trabalho. O estudo contou com uma amostra de 1.710 sujeitos: 769 estudantes matriculados em cursos de graduação em Ciências Contábeis em IES brasileiras e 941 contadores registrados nos Conselhos Regionais de Contabilidade de várias regiões brasileiras, que responderam ao questionário desenvolvido por Lin, Xiong e Liu (2005) sobre a importância atribuída pelos respondentes aos quesitos conhecimento, habilidades e métodos de ensino-aprendizagem. Os resultados encontrados evidenciaram maiores níveis de importância percebida pelos profissionais (quando comparados aos estudantes) nos quesitos investigados. Comparativamente com a China e com os EUA, os escores dos profissionais brasileiros são sempre maiores para as três dimensões (conhecimentos, habilidades e métodos). Os estudantes brasileiros em comparação com os chineses, de forma geral, também atribuem maior importância para as três dimensões analisadas. Os elevados escores apontados pelos respondentes brasileiros merecem atenção por parte dos gestores das IES, levando em conta a intensidade das mudanças de perfil dos jovens estudantes e a velocidade das alterações do mercado profissional. Destaque-se que esses resultados devem ser mais explorados, analisando-se as suas razões, inferindo-se que 
o contexto atual da Contabilidade no Brasil, decorrente do processo global de harmonização das normas internacionais, é cenário propício para explicações a esse respeito.

Palavras-chave: Conhecimentos. Habilidades. Ensino-aprendizagem. Contabilidade.

\section{ABSTRACT}

Driven by Albrecht and Sack (2000), Francis and Kelly (2002) and based on Bloom's Taxonomy (1956), this study aims to compare perceptions of Accountancy undergraduate students and accounting professionals in Brazil about the set of knowledge, skills and methods of teaching and learning that are considered the most important for accountants' professional activities. The study involved a sample of 1,710 subjects: 769 students enrolled in undergraduate accounting programs in Brazilian universities and 941 accountants registered in Regional Accounting Councils from several Brazilian regions, who responded the questionnaire developed by Lin, Liu and Xiong (2005) about the importance attributed to knowledge, skills and teaching and learning methods. The results showed that the professionals perceived all investigated topics as more important when compared to students. Compared with China and the U.S., the scores of Brazilian professionals are always higher for the three dimensions (knowledge, skills and methods). In comparison with the Chinese, the Brazilian students generally also assign more importance to the three dimensions examined. Higher education managers should pay attention to the Brazilian participants' higher scores, considering the intense changes in young students' profiles and the accelerated professional market changes. It is highlighted that these results should be further explored by analyzing their reasons, inferring that the current Accounting context in Brazil, due to the global process of harmonization of international standards, is a favorable scenario for explanations in this respect.

Keywords: Knowledge. Skills. Teaching and learning. Accounting..

\section{INTRODUÇÃO}

Desenvolver profissionais competentes é um dos objetivos da educação contábil. Para a International Federation of Accountants (2010), por meio do International Accounting Education Standards Board (IAESB), a competência é definida como a capacidade de desempenhar um papel obedecendo a um determinado padrão de referência. Para demonstrar a sua competência, um contador deve possuir o conhecimento e a qualificação profissional necessários, além de valores e atitudes éticas (IFAC, 2010). Levando em conta que a competência para atuar no campo profissional requer um nível adequado de conhecimento, habilidades, valores, ética e atitudes, faz-se necessário adentrar no campo da educação contábil. Nesse contexto, entende-se a educação como um processo sistemático que tem o objetivo de desenvolver conhecimen- tos, habilidades e atitudes e objetiva, dentre outros, dotar o indivíduo de competência visando ao seu sucesso profissional.

Órgãos e pesquisadores internacionais da contabilidade têm debatido a educação na área contábil por quase duas décadas (AECC, 1990; AICPA, 1998; ALBRECHT; SACK, 2000; BURNETT, 2003), destacando o problema de que o currículo de contabilidade tem pouca relevância para a prática contábil. Para esses órgãos e pesquisadores, o conteúdo do currículo e o desenvolvimento dos conhecimentos, das habilidades e das atitudes dos discentes devem ser revistos de forma que possam se adequar às demandas do mercado profissional, em um ambiente de negócios em constante mudança.

O Core Competency Framework, desenvolvido pelo American Institute of Certified 
Public Accountants (AICPA, 2010), define um conjunto de competências com base em capacidades necessárias aos alunos para o futuro exercício da profissão contábil, independente da carreira que escolherem na área da contabilidade. O Core Competency Framework tem seu foco nas habilidades necessárias para os alunos adquirirem os conhecimentos que os conduzirão ao sucesso profissional. Dessa forma, apresenta um currículo baseado em habilidades que terão valor no longo prazo, e não em conhecimentos, entendendo-se que as habilidades conduzirão o aluno ao desenvolvimento dos conhecimentos, que podem variar no futuro.

Albrecht e Sack (2000) avaliam a evasão de estudantes dos cursos de Contabilidade norte-americanos, evidenciando a indesejável distância entre os conhecimentos adquiridos e a formação necessária para a atuação profissional. Essa distância pode estar representada por vários fatores, dentre eles, os conhecimentos transmitidos, as habilidades ensinadas e as metodologias de ensino-aprendizagem utilizadas pelas IES, apontando para um confronto entre o ensino e a realidade do mercado profissional e indicando dificuldades das IES em reproduzir ambientes organizacionais.

Francisco e Kelly (2002) estenderam o estudo sobre a educação contábil realizado por Albrecht e Sack (2000), examinando de perto a questão do desenvolvimento de habilidades no ensino da Contabilidade a partir da percepção de estudantes. Os autores identificaram que a diferença na percepção da importância de uma série de competências entre os profissionais de Contabilidade, educadores e alunos era muito pequena nos EUA. Em particular, os estudantes de Contabilidade concordaram com muitas das mesmas habilidades apontadas pelos respondentes profissionais.

Em um sistema substancialmente diferente dos EUA, Lin e Deng (1991) observaram que a educação contábil na China, que se encontra sob uma economia centralizada, teve, por muitos anos, o objetivo de treinar um gran- de número de pessoas para executar funções simples de Contabilidade, sujeitas a normas e regras restritivas formuladas pelas autoridades governamentais (assim como no Brasil antes do processo de harmonização contábil). A base de conhecimento, nesse período, foi, portanto, restrita e não contribuiu para o desenvolvimento de habilidades dos profissionais da Contabilidade (TANG, 1997).

Assim como Francisco e Kelly (2002), Lin, Xiong e Liu (2005) examinaram a importância dos conhecimentos, habilidades e metodologias de ensino-aprendizagem para a educação contábil na China na visão dos profissionais, educadores e estudantes de Contabilidade. Os autores apontam que os entrevistados, em geral, estão de acordo em vários pontos, em especial com os conhecimentos e habilidades que devem ser desenvolvidos na educação contábil chinesa, confirmando o exposto por Tang (1997) sobre o limitado desenvolvimento do conhecimento e das habilidades. Lin, Xiong e Liu (2005) reforçam a necessidade de uma reforma na educação contábil da China, redesenhando currículo e propondo métodos de ensino e aprendizagem eficientes, considerando a demanda por profissionais de contabilidade com um vasto conjunto de conhecimentos e competências para o novo ambiente de negócios do país.

Howieson (2003) afirma que os educadores devem antecipar as mudanças esperadas nas competências e habilidades dos contadores e desenvolver cursos e métodos de ensino com orientação mais interdisciplinar e analítica, visando ao mercado de trabalho. Segundo Albrecht e Sack (2000), vários líderes na área contábil consideram a atual estrutura da educação contábil desatualizada e com necessidade de mudanças significativas.

Essas mudanças requerem, ainda, uma análise dos objetivos educacionais na área contábil. Um dos principais estudos sobre objetivos educacionais é o de Bloom (1956), que apresenta uma estrutura de organização hierárquica de objetivos educacionais represen- 
tados pelas possibilidades de aprendizagem em três grandes domínios: cognitivo, afetivo e psicomotor. O domínio cognitivo inclui os objetivos educacionais que lidam, em geral, com o desenvolvimento do conhecimento, das habilidades intelectuais e das competências. O domínio afetivo trata de reações de ordem afetiva e de empatia, abrangendo os aspectos de atitudes e sensibilização (KRATHWOHL; BLOOM; MASIA, 1964). O domínio psicomotor abrange as habilidades na execução de tarefas. Os conceitos que compõem o conjunto da "Taxonomia de Bloom", como é conhecido o estudo desenvolvido pelo autor na década de 1950, são úteis e relevantes para o planejamento de modelos de formação, ensino, aprendizagem e avaliação do processo educacional.

No cenário brasileiro, a Resolução do Conselho Nacional de Educação CNE/CES No. 10/2004 define as Diretrizes Curriculares a serem observadas pelas Instituições de Ensino Superior (IES) na elaboração da matriz curricular do curso de Ciências Contábeis. A Resolução trata do perfil desejado do formado, das competências e habilidades desejadas, e dos conteúdos curriculares, de forma a atender às necessidades e demandas dos alunos, do mercado e da sociedade. A preocupação com as demandas do mercado de trabalho na área contábil, no cenário brasileiro, justifica-se pelas constantes alterações no ambiente de negócios do país, considerando, ainda, sua atual posição econômica no contexto mundial. Dentre essas alterações, destaque-se, no âmbito acadêmico e corporativo, o processo de convergência aos padrões internacionais de Contabilidade, apoiado nas Leis $n^{\circ} 11.638 / 07$ e $n^{\circ} 11.941 / 09$, além dos Pronunciamentos Técnicos emitidos pelo Comitê de Pronunciamentos Contábeis (CPC), a partir de 2008.

Além disso, cabe ressaltar que EUA, China e Brasil têm destaque no cenário econômico mundial, com reflexo na demanda por profissionais de Contabilidade credenciados internacionalmente. Assim, evidencia-se a importância da adequação dos diplomados no campo da prática contábil, devendo fazer parte integrante do processo educativo liderado pelos gestores das instituições de ensino a atualização e a constante revisão de seus programas para inserir conhecimentos e habilidades que promovam o reconhecimento internacional dos profissionais contadores.

Com base na taxonomia de Bloom (1956) e em estudos sobre os conhecimentos, as habilidades e as metodologias de ensino-aprendizagem para a educação contábil (ALBRECHT; SACK, 2000; FRANCISCO; KELLY, 2002; LIN; XIONG; LIU, 2005), a pesquisa propõe-se a responder à seguinte questão: em que medida os conhecimentos, habilidades e métodos de ensino-aprendizagem são percebidos de forma diferenciada para a atuação profissional do contador, por estudantes de graduação em Ciências Contábeis e profissionais de Contabilidade brasileiros? Nesse sentido, o objetivo geral deste estudo consiste em comparar a percepção de estudantes de cursos de Ciências Contábeis em IES brasileiras e profissionais da contabilidade no Brasil quanto aos conhecimentos, habilidades e métodos de ensino-aprendizagem considerados como mais importantes para a atuação do contador no mercado de trabalho.

Esta pesquisa se justifica ao discutir a educação contábil e seu reflexo no mercado profissional, na percepção dos estudantes de IES brasileiras e dos profissionais que atuam no mercado, e os resultados obtidos são comparados com as pesquisas de Francisco e Kelly (2002) e de Lin, Xiong e Liu (2005) quanto aos conhecimentos, habilidades $\mathrm{e}$ métodos de ensino-aprendizagem percebidos pelos profissionais e pelos estudantes nos EUA e na China. Destaque-se sua relevância para a área, uma vez que está completamente alinhado às diretrizes estratégicas do International Federation of Accountants para 2010-2012 (INTERNATIONAL FEDERATION OF ACCOUNTANTS - IFAC, 2010a). Além disso, as comparações presentes nesta 
pesquisa são de grande importância para $o$ avanço da área de educação contábil no Brasil, uma vez que apresentam e explicam relações entre nações com economias integradas e em expansão num contexto mundial, portanto, em que a presença da Contabilidade é fundamental e estratégica para fomentar tal desenvolvimento.

\section{REFERENCIAL TEÓRICO}

Nas últimas décadas têm sido recorrentes os debates de pesquisadores, educadores, profissionais e empregadores, sobre a capacidade das Instituições de Ensino Superior (IES) em preparar, adequadamente, os estudantes da área contábil para o mercado de trabalho cada vez mais complexo e dinâmico (NELSON; BAILEY; NELSON, 1998; PORTER; CARR, 1999; BOLT-LEE; FOSTER, 2003; MCCHLERY, PAISEY, 2003; HASSAL, et al. 2003; CARR; CHUA; PERERA, 2004).

Nelson, Bailey e Nelson (1998) mencionam que inúmeras críticas têm sido feitas quanto ao perfil dos egressos dos cursos de contabilidade, sendo propostos movimentos em favor de mudanças, tanto nos curricula como nas técnicas pedagógicas, visando à formação de profissionais competentes $\mathrm{e}$ competitivos.

Para Bolt-Lee e Foster (2003), as discussões sobre a necessidade de promover alterações na educação contábil intensificaram-se na década de 1980, quando os profissionais passaram a culpar as Instituições de Ensino de não tê-los preparado suficientemente para enfrentar as pressões advindas de um mercado fortemente regulamentado, as mudanças no ambiente de negócios e os avanços da tecnologia da informação.

Carr, Chua e Perera (2004) alinham dois fatores principais que podem explicar os problemas existentes na educação contábil atualmente: a pouca atenção dada ao desenho dos programas dos cursos de contabilidade e a pequena ou nenhuma preocupação com as necessidades dos stakeholders do processo de formação contábil. Os autores argumentam que deve ser considerada a visão do aluno, do mercado, do governo, entre outras, e que as
IES, também, devem levar em consideração a opinião de uma rede de stakeholders tão ampla quanto possível durante o processo de criação dos cursos, pois o desalinhamento entre o perfil apresentado pelo graduado em contabilidade e o requerido no mercado de trabalho parece ser, na opinião de diversos autores (HASSAL et al. 2003; MORGAN, 1997; MOHAMED; LASHINE, 2003; ARQUERO et al., 2007; ALBRECHT; SACK, 2000), a principal fonte das críticas dirigidas ao ensino contábil.

Com perspectiva global profissional sobre competência e experiência prática de contadores nas diversas áreas da Contabilidade, Needles Jr. et al. (2001) desenvolveram estudo relacionado à diretiva do IFAC (International Education Guideline Number 9) que explora a necessidade de foco em ações de implementação, apoiando programas educacionais, professores e administradores. O estudo reforça a importância de desenvolvimento contínuo (pela vida), em razão das acentuadas transformações na profissão, com efeito sobre requisitos de conhecimentos, habilidades e atitudes do contador.

O Handbook de Educação Internacional da International Federation of Accountants (IFAC, 2010) contempla o framework dos padrões internacionais de educação para os profissionais da contabilidade (International Education Standards for Professional Accountants) e estabelece os conceitos utilizados pelo International Accounting Education Standards Board (IAESB) em suas publicações.

No International Education Standard 2, o documento da IFAC (2010) enfatiza que os alunos devem adquirir conhecimentos, habilidades, valores, ética e atitude profis- 
sional, e serem capazes de integrar esses elementos, e que o componente conhecimento do programa de educação contábil profissional, igualmente, pode ser usado para desenvolver habilidades profissionais. Os conhecimentos que devem ser apresentados pelos contadores são agrupados como segue: (a) conhecimentos de contabilidade, finanças e áreas afins (contabilidade financeira e relatórios, contabilidade gerencial, tributação, direito comercial, auditoria, finanças e gestão financeira e ética profissional); (b) conhecimentos acerca das organizações e dos negócios (economia, governança corporativa, ambiente de negócios, ética, métodos quantitativos, mercado financeiro, comportamento organizacional, tomada de decisões gerenciais e estratégicas, marketing e negócios internacionais e globalização; (c) conhecimentos sobre tecnologia da informação (conhecimentos que permitem ao profissional utilizar, avaliar, estruturar e gerenciar sistemas de informações informatizados).

As habilidades que devem ser adquiridas e desenvolvidas pelo profissional contábil estão dispostas no International Education Standard 3 (IFAC, 2010) e são segregadas em: (a) intelectuais (contribuem para solucionar problemas, tomar decisões e julgar situações complexas); (b) técnicas e funcionais (compreendem as habilidades gerais e específicas de contabilidade); (c) pessoais (compreendem as atitudes e comportamentos do profissional contábil que proporcionam melhoria na sua aprendizagem pessoal e profissional); (d) interpessoais e de comunicação (permitem que o profissional interaja com outras áreas de conhecimento, receba e transmita informações, forme julgamentos e tome decisões); (e) organizacionais e de gerenciamento de negócios (são as habilidades relacionadas ao funcionamento da organização). Além dos conhecimentos e habilidades apresentados, a IFAC ressalta a importância da postura ética do profissional contábil, enfatizando que o comportamento ético é tão importante quanto as competências técnicas (IFAC, 2010).

Numa mesma linha, o Core Competency Framework emanado do American Institute of Certified Public Accountants (AICPA, 2010) contempla um modelo de competências-chave que devem ser apresentadas pelos contadores ao ingressarem no mercado de trabalho. Bolt-Lee e Foster (2003) assinalam que as recomendações do modelo são o resultado de opinião de mais de três mil profissionais contábeis. As competências definidas pelo AICPA compreendem: (a) competências funcionais, que correspondem às competências técnicas (modelagem de decisões, análise de risco, mensuração e relatórios); (b) competências pessoais, que dizem respeito aos comportamentos e atitudes que podem melhorar a forma como os indivíduos se relacionam com os demais e facilitar o aprendizado individual (pesquisa, uso da tecnologia da informação, comportamento profissional, resolução de problemas e tomada de decisão, interação, liderança e comunicação); (c) competências relacionadas aos negócios, que levam em consideração a compreensão do ambiente interno e ambiente externo dos negócios (visão do setor, pensamento crítico e estratégico, perspectiva global, perspectiva legal, marketing com foco no cliente, uso da tecnologia da informação).

Já a Accounting Education Change Commission (AECC), diante da preocupação decorrente da falta de aderência entre as qualificações apresentadas pelos graduados em contabilidade e aquelas requeridas pelo mercado de trabalho, expôs, em um relatório elaborado em 1999, os conhecimentos e habilidades consideradas necessárias ao exercício da profissão contábil, que deveriam ser desenvolvidas pelas Instituições de Ensino. As habilidades esperadas do profissional, segundo entendimento da AECC (1999), são: (a) habilidade de comunicação; (b) habilidades intelectuais e (c) habilidades interpessoais. Além das habilidades mencionadas, 
a AECC (1999) esclarece em seu relatório que, ao ingressarem no mercado de trabalho profissional, os contadores deveriam possuir um amplo grupo de conhecimentos divididos em três áreas: (a) conhecimentos gerais; (b) conhecimentos organizacionais e de negócios e (c) conhecimentos sobre contabilidade e auditoria.

Uma das contribuições relevantes para o planejamento, a organização e o controle dos objetivos de aprendizagem, que apoia programas acadêmicos na definição de perfil de um profissional competente, teve origem na taxonomia sobre objetivos educacionais de Bloom (1956), representada pelas possibilidades de aprendizagem nos domínios cognitivo, afetivo e psicomotor. Como já exposto na Introdução, para fins deste estudo, são utilizados os conceitos do domínio cognitivo, que envolve o desenvolvimento do conhecimento, das habilidades intelectuais e das competências e contempla uma hierarquia de seis níveis: a) conhecimento; b) compreensão; c) aplicação; d) análise; e) síntese e f) avaliação. Esses níveis de hierarquia, organizados do mais simples (conhecimento), que é ter a informação, ao mais complexo (avaliação), que implica julgamento sobre o valor e a importância de uma ideia, têm sido questionados. Marzano (2000) afirma que esses níveis podem simplesmente não significar a realidade dos processos cognitivos, pois cada elemento da taxonomia tem seus próprios objetivos e valores. Anderson et al. (2001) argumentam que praticamente todas as atividades de ensino complexas requerem o uso de várias capacitações cognitivas diferentes.

Ausubel (2003) entende que os indivíduos desencadeiam seus conhecimentos de uma forma hierárquica, em que o conceito mais geral tem papel de destaque e os conceitos ditos auxiliares estão a ele relacionados dentro dessa cadeia. Em uma versão atualizada da Taxonomia de Bloom, Anderson et al. (2001) consideram uma gama maior de fatores que afetam o ensino e a aprendizagem, diferenciando o "conteúdo do raciocínio" dos "procedimentos aplicados para resolver problemas".

Ao tratar do ensino da contabilidade em nível superior, a Accounting Education Change Commission (AECC, 1990) argumenta que os estudantes deveriam ter conhecimento geral, organizacional e de negócios, além de um excelente conhecimento contábil. A AECC (1990) entende que uma adequada compreensão da contabilidade inclui: a) habilidade na identificação de objetivos, problemas e oportunidades; b) habilidade para identificar, recolher, mensurar, sumarizar, verificar, analisar e interpretar dados financeiros e não financeiros; c) habilidade para usar dados, exercer julgamentos, avaliar riscos e resolver problemas do mundo real. Para tal, deve desenvolver pensamento analítico e conceitual e não somente memorizar padrões profissionais.

Em pesquisa realizada na CEO, Albrecht e Sack (2000) constataram que os contadores usam $90 \%$ de seu tempo para a elaboração de informações que se destinam a usuários externos, as quais nada têm a ver com a forma com que esses gerenciam os negócios. Para os $\mathrm{CEO}$, tanto a profissão contábil como a educação contábil têm sofrido um processo de marginalização, argumentando que os CFO, diferentemente dos típicos contadores, compreendem os elementos dos negócios da organização, como os gestores tomam decisões e quais as informações que necessitam para tal. Com isso, reforçam a convicção de que a educação contábil não tem mudado com a rapidez desejada para atender às demandas do mundo dos negócios e esse muda de forma mais acentuada que o conhecimento, aptidões e habilidades necessárias que os contadores deveriam ter para atenderem tais demandas. Mohamed e Lashine (2003), também, aduzem que o corrente e emergente desenvolvimento no mundo dos negócios requer melhoria substancial no nível de competência dos contadores, o que pode ser obtido, 
melhorando os conhecimentos e habilidades relativas ao ensino contábil.

Porter e Carr (1999) divulgaram os resultados de uma pesquisa na Nova Zelândia envolvendo estudantes presentes e futuros, empregadores, entidades de classe interessadas nos cursos e nos graduados em Contabilidade, autoridades reguladoras e comunidade local e acadêmica, destinada a conhecer os atributos, conhecimentos e habilidades que eles consideravam importantes para o exercício da profissão contábil. Além dos conhecimentos técnicos requeridos pelo órgão que regula a profissão contábil naquele País, a pesquisa revelou que os profissionais deveriam apresentar, entre outras: (a) capacidade de aplicar na prática as habilidades adquiridas; (b) habilidade para resolver problemas; (c) habilidade de análise e síntese; (d) habilidades interpessoais e de comunicação; (e) conhecimento de diferentes culturas e línguas estrangeiras; (f) conhecimentos de administração estratégica e (g) habilidade de gerenciar equipes, melhorando o desempenho e a dinâmica dos grupos de trabalho. Os autores enfatizam que os graduados deveriam possuir profundos conhecimentos de matérias básicas de contabilidade, conhecimentos sobre administração de negócios e de tecnologia da informação e habilidades de raciocinar de forma analítica e crítica.

Profissionais da área contábil, ao serem indagados por Albrecht e Sack (2000) sobre as atividades mais demandadas dos graduados em contabilidade, mencionaram que essas deveriam ser, nessa ordem: (a) Análise financeira; (b) Planejamento financeiro; (c) Elaboração de demonstrações contábeis; (d) Consultoria estratégica e (e) Consultoria de sistemas. Os educadores, que também participaram na pesquisa, consideraram os serviços de auditoria como de maior demanda.

Albrecht e Sack (2000), também, procuraram conhecer, na opinião dos profissionais e dos educadores, a demanda por determinados tipos de atividades ligadas à Contabilida- de. Tanto os profissionais como os professores concordaram que, enquanto a demanda por atividades relacionadas à auditoria interna tradicional, contabilidade/finanças corporativas, contabilidade tributária e serviços de auditoria permanecessem estáveis, novas atividades surgiriam como: planejamento estratégico e consultoria. Para os autores, o mundo dos negócios tem mudado de forma mais acentuada que o conhecimento, aptidões e habilidades providas pela educação contábil. Os resultados da pesquisa sugerem a necessidade de adotar métodos de ensino mais criativos (trabalhos em equipe desenvolvidos em companhias, apresentações orais, exercícios escritos e envolvimento de profissionais de negócios em sala de aula).

Mohamed e Lashine (2003), também, partilham desse pensamento, ao constatarem que o desenvolvimento, no mundo dos negócios, requer uma melhoria substancial no nível de competência dos contadores, o que implica qualificar os conhecimentos e as habilidades relativas ao ensino contábil. Mencionam que o mercado global requer que os profissionais adquiram e desenvolvam habilidades de comunicação, computacionais, analíticas, intelectuais, multidisciplinares e interdisciplinares, conhecimentos de assuntos globais, qualidades pessoais e pensamento crítico.

Em consonância com o estudo de Albrecht e Sack (2000) sobre a educação contábil, Francisco e Kelly (2002) desenvolveram uma pesquisa com 223 estudantes de contabilidade e de outros cursos da área de negócios em uma universidade norte-americana, objetivando verificar se ambos os coletivos avaliavam de forma idêntica a importância do desenvolvimento de habilidades para o seu futuro exercício profissional ou se havia diferença de percepção a respeito. Adicionalmente, o estudo averiguou se as habilidades consideradas como mais importantes pelos profissionais, segundo pesquisa de $\mathrm{Al}-$ brecht e Sack (2000), também o eram para os estudantes. 
Os resultados da pesquisa de Francisco e Kelly (2002) apontam que os estudantes de Contabilidade consideraram a comunicação escrita e oral como as habilidades mais importantes a serem desenvolvidas. Os demais estudantes da área de negócios consideraram a comunicação escrita como a sexta habilidade mais importante, observando-se maior proximidade na avaliação de ambos sobre a importância da comunicação oral. A tomada de decisão foi considerada pelos estudantes da área de negócios como a principal habilidade a ser desenvolvida, tendo sido avaliada pelos estudantes de contabilidade como a terceira mais importante. As habilidades interpessoais foram consideradas pelos dois grupos de estudantes como importantes, observando-se maior discrepância em relação à habilidade de trabalho em equipe, considerada pelos estudantes de contabilidade como de menor importância, o que sugere o seu entendimento de que os problemas devem ser analisados de forma individual.

Francisco e Kelly (2002) destacam que os estudantes de contabilidade consideraram relevantes praticamente as mesmas habilidades identificadas pelos profissionais (comunicação escrita, oral e raciocínio crítico/analítico), na pesquisa realizada por Albrecht e Sack (2000). Smythe e Nikolai (2002), em pesquisa realizada com estudantes de graduação, pósgraduação e profissionais contábeis, confirmam a importância da habilidade "comunicação", afirmando que o seu desenvolvimento constitui um dos aspectos relevantes a ser observado no processo da educação contábil.

Ressalte-se que habilidades de comunicação e interpessoais, além de um bom entendimento de todas as fases do negócio e visão sistêmica, também são destacadas por Siegel e Kulesza (1996), na medida em que o ambiente de trabalho requer profissionais contábeis que trabalhem com equipes multifuncionais, pois devem ser capazes de compreender e explicar os impactos das atividades de marketing, engenharia, produção e demais áreas na situação econômico-financeira da organização.
Lin, Xiong e Liu (2005) desenvolveram, em 2003, uma pesquisa, seguindo os estudos realizados anteriormente por Albrecht e Sack (2000) e por Francisco e Kelly (2002), com o objetivo de conhecer a percepção de estudantes, professores e profissionais chineses quanto à importância dos conhecimentos, habilidades e métodos de ensino-aprendizagem para a atuação profissional do contador, considerando que as significativas mudanças ocorridas no âmbito de negócios na China estão expandindo a demanda por novos profissionais e, em consequência, gerando novas exigências na formação desses profissionais.

Os estudantes chineses, segundo Lin, Xiong e Liu (2005), apontaram a contabilidade financeira (societária), finanças, contabilidade gerencial, tributação, legislação comercial, auditoria e serviços de seguros, ética e responsabilidade social, sistemas de informação, negócios globais e comércio eletrônico como os dez conhecimentos mais importantes. O ranking dos três principais componentes do conhecimento, na percepção dos estudantes (contabilidade financeira, finanças e tributação), é relativamente consistente com o que foi apontado nas pesquisas de Albrecht e Sack (2000) e Francisco e Kelly (2002). Por outro lado, há substanciais diferenças quanto aos conhecimentos sobre sistemas de informação, legislação comercial e ética e responsabilidade social, na visão dos estudantes. As dez habilidades mais importantes identificadas foram: comportamento profissional, técnicas computacionais, língua estrangeira, habilidades interpessoais, tomada de decisão, raciocínio crítico/analítico, comunicação escrita, trabalho em equipe, liderança e comunicação oral; e os três mais importantes métodos de ensino-aprendizagem, segundo os estudantes chineses, foram a análise de informações, atividades nas empresas e análise de casos (LIN; XIONG; LIU, 2005).

Resultados similares sobre a percepção de profissionais chineses quanto à importância dos conhecimentos, habilidades e métodos 
de ensino-aprendizagem para a atuação profissional do contador foram apontados, no estudo de Lin, Xiong e Liu (2005). Os profissionais consideraram os conhecimentos sobre contabilidade financeira (societária), finanças, tributação e contabilidade gerencial como os mais importantes; comportamento profissional, técnicas computacionais, comunicação escrita e raciocínio analítico/crítico, como as habilidades mais importantes; análises de informações, análise de casos e atividades nas empresas como métodos de ensinoaprendizagem relevantes.

Lin, Xiong e Liu (2005) constataram que os escores médios dos itens relacionados com conhecimentos foram substancialmente superiores aos das habilidades, especialmente, raciocínio crítico/analítico, tomada de decisão e comunicação escrita e oral, levando a crer que o ensino de contabilidade naquele país ainda está focado no conhecimento tradicional.

Do exposto, pode-se observar que a literatura apresenta ligação coerente e forte entre os elementos de conhecimento, habilidades e atitudes e competências de profissionais da área de negócios e contabilidade, destacandose pesquisa em que tais elementos são enfatizados em ambiente de atuação profissional global e transversalmente entre as áreas de atuação profissional (PALMER; ZIEGENFUSS; PINSKER, 2004).

No Brasil, a Resolução CNE/CES N ${ }^{\circ}$ 10/2004 instituiu as Diretrizes Curriculares Nacionais do Curso de Graduação em Ciências Contábeis, que devem ser seguidas pelas Instituições de Ensino Superior (IES) na elaboração do Projeto Pedagógico do curso. Esse deve contemplar o perfil desejado do egresso em termos de competências e habilidades, que incluem, entre outras: (a) utilização adequada da terminologia e linguagem das ciências contábeis e atuariais; (b) visão sistêmica e interdisciplinar da atividade contábil; (c) aplicação adequada da legislação inerente às funções contábeis; (d) liderança de equipes multidisciplinares; (e) desenvolvimento, análise e implantação de sistemas de informação contábil e de controle gerencial, devendo revelar capacidade crítico-analítica ao avaliar as implicações organizacionais decorrentes do uso da tecnologia da informação. Essas Diretrizes foram concebidas levando em conta o cenário de mudanças no mundo dos negócios, de forma geral, e no Brasil de forma particular, com reflexos sobre a demanda dos profissionais da Contabilidade.

Nesse contexto, ressalte-se a relevância em investigar os conhecimentos, as habilidades e os métodos de ensino-aprendizagem na percepção dos estudantes e dos profissionais de Contabilidade no Brasil, considerando o cenário atual de grandes desafios para a profissão diante do processo de convergência da contabilidade brasileira aos padrões internacionais. Ressalte-se, ainda, que, recentemente, foi promulgada uma lei federal (Lei No $12.249 / 10)$ que exige a realização de exame de suficiência para o exercício da profissão contábil no Brasil. Esse Exame não se configura somente como uma prova que visa medir conhecimentos para permitir ao candidato atuar no mercado profissional, mas, segundo o Conselho Federal de Contabilidade (CFC, 2010), órgão regulador da profissão contábil no país, deverá "estimular a modernização das Instituições de Ensino e dos currículos dos cursos de Ciências Contábeis”.

\section{METODOLOGIA}

\subsection{Tipologia da pesquisa}

Este estudo comparativo pode ser caracterizado como de natureza descritiva, correlacional e quantitativa, conforme a classificação de Sampieri, Collado e Lucio (2006). Essa natureza está diretamente relacionada com o objetivo da pesquisa de comparar percepções de grupos de indivíduos distintos de maneira in- 
dependente ou conjunta. Adicionalmente, esse tipo de estudo pode oferecer a oportunidade de relações com variáveis ainda pouco elaboradas permitindo indicar algumas tendências.

A abordagem metodológica empregada no estudo é a teórico-empírica, respeitandose os critérios de cientificidade e a capacidade de encontrar evidências que sejam suficientes para avançar o campo de estudo e permitir inferências, sem abandonar o arcabouço teórico (GALL; GALL; BORG, 2003; MARTINS; THEÓPHILO, 2009).

\subsection{Hipóteses}

A discussão sobre as exigências do mercado de trabalho na área de Ciências Contábeis afeta diretamente a educação contábil, considerando que esse mercado é formado por profissionais oriundos de IES que estão se adaptando ao atual cenário da Contabilidade no país.

Nesse contexto, com o incentivo dos estudos de Albrecht; Sack, 2000; Francisco; Kelly, 2002 e com base na Taxonomia de Bloom (1956), busca-se resposta à questão de pesquisa já apresentada, além de investigar a relação entre as percepções de estudantes e profissionais da área de Ciências Contábeis e algumas características dos respondentes como gênero, tipo de instituição em que cursou o ensino médio (pública ou privada), tempo dedicado ao estudo, vínculo empregatício e turno do curso de graduação relativo aos primeiros e gênero, faixa etária, tempo de exercício da profissão e titulação relativo aos últimos.

Como ficou definido desde o início que o estudo seria de natureza correlacional e descritiva, surgiu a necessidade de formular hipóteses. Dessa forma, as hipóteses estabelecidas, a seguir, derivam da Taxonomia de Bloom (1956), permitindo comparar os resultados com as evidências empíricas encontradas por Albrecht; Sack, 2000; Francisco; Kelly, 2002 e foram utilizadas para guiar os pesquisadores.
As três primeiras hipóteses (direcionais) deste estudo estão relacionadas à percepção entre profissionais quanto à maior importância percebida por eles (em relação aos estudantes) sobre conhecimentos, habilidades e métodos de ensino-aprendizagem.

$\mathrm{H}_{1}$ : Profissionais percebem maior importância dos conhecimentos quando comparados aos estudantes.

$\mathrm{H}_{2}$ : Profissionais percebem maior importância das habilidades quando comparados aos estudantes.

$\mathrm{H}_{3}$ : Profissionais percebem maior importância dos métodos de ensino-aprendizagem quando comparados aos estudantes.

O segundo grupo de hipóteses relaciona a percepção de importância dos estudantes e as categorias como gênero, vínculo empregatício e turno do curso.

$\mathrm{H}_{4}$ : Há diferenças significativas entre as percepções de importância dos estudantes quanto aos conhecimentos, habilidades e métodos de ensino-aprendizagem em função do gênero.

$\mathrm{H}_{5}$ : Há diferenças significativas entre as percepções de importância dos estudantes quanto aos conhecimentos, habilidades e métodos de ensino-aprendizagem em função de vínculo empregatício.

$\mathrm{H}_{6}$ : Há diferenças significativas entre as percepções de importância dos estudantes quanto aos conhecimentos, habilidades e métodos de ensino-aprendizagem em função do turno do curso (diurno ou noturno).

O último conjunto de hipóteses relaciona a percepção de importância dos profissionais e as categorias como gênero, tempo de exercício da profissão e titulação.

$\mathrm{H}_{7}$ : Há diferenças significativas entre as percepções de importância dos profissionais quanto aos conhecimentos, habilidades e métodos de ensino-aprendizagem em função do gênero.

$\mathrm{H}_{8}$ : Há diferenças significativas entre as percepções de importância dos profissionais quanto aos conhecimentos, habilidades e mé- 
todos de ensino-aprendizagem em função do tempo de exercício da profissão.

$\mathrm{H}_{9}$ : Há diferenças significativas entre as percepções de importância dos profissionais quanto aos conhecimentos, habilidades e métodos de ensino-aprendizagem em função da titulação.

Para testar a validade das hipóteses foram realizados testes estatísticos empregando o software SPSS $^{\circ}$, adotando o nível de significância $0,05(\alpha=0,05)$.

\subsection{Amostra, instrumento de coleta de dados e procedimentos}

A amostra deste estudo, de natureza nãoprobabilística, é composta por 1.710 sujeitos: 769 estudantes matriculados em cursos de graduação em Ciências Contábeis em Instituições de Ensino Superior (IES) brasileiras e por 941 contadores registrados nos Conselhos Regionais de Contabilidade de várias regiões brasileiras. As IES, os estudantes e os profissionais foram selecionados utilizando critérios de acessibilidade, o que requer cuidados para fazer inferências, pois a população da qual a amostra foi selecionada pode ser substancialmente diferente. Como a ciência não oferece a oportunidade de prova absoluta, uma amostragem probabilística não garantiria que fosse (SELLTIZ; WRIGHTSMAN; COOK, 1987).

Os dados foram coletados durante os meses de outubro, novembro e dezembro de 2010 de duas formas distintas. Os estudantes responderam ao questionário impresso, que foi aplicado presencialmente pelos pesquisadores com o consentimento dos docentes das disciplinas, e os profissionais responderam ao questionário via correio eletrônico.

Para facilitar as análises comparativas, foi utilizado o questionário desenvolvido por Lin, Xiong e Liu (2005), contribuindo com a função descritiva da pesquisa que é dependente do trabalho de observação de outros pesquisadores para o aperfeiçoamento dos instrumentos de mensuração e observação (GALL;
GALL; BORG, 2003). Testes-piloto foram conduzidos com estudantes de graduação $\mathrm{e}$ representantes dos profissionais da área contábil, tendo sido feitas pequenas adaptações em benefício da compreensão, na linguagem e no formato. Não foram enfrentados maiores problemas em termos de validade e confiabilidade do instrumento; o que foi confirmado pelos testes-piloto. Todos os indivíduos pesquisados tiveram participação voluntária e concordaram com o termo de consentimento inserido no final do instrumento, de acordo com os procedimentos de pesquisa usuais exigidos pelas instituições envolvidas e as recomendações quanto às implicações éticas evidenciadas por Selltiz, Wrightsman e Cook (1987a) e Creswell (2003).

Os alunos e os profissionais responderam a um instrumento de coleta de dados que consistia em três partes: informação geral sobre o participante; lista de conhecimentos, habilidades e métodos de ensino-aprendizagem (44 itens) e termo de consentimento. As variáveis referentes às informações gerais sobre os estudantes contemplavam: turno do curso (noturno ou diurno), período no curso (semestre acadêmico), gênero, ensino médio (público ou privado), situação profissional, função profissional relacionada à contabilidade, remuneração e tempo de estudo semanal (além do tempo em sala de aula); as referentes às informações gerais sobre os profissionais contemplavam: faixa etária, gênero, tempo de exercício da profissão, principal atividade remunerada, tipo de instituição que cursou o ensino superior e maior titulação. Nos 44 itens relacionados à segunda parte do instrumento, os participantes expressaram sua percepção sobre a relevância em termos de conhecimento, habilidades e métodos de ensino aprendizagem para a atuação profissional do contador, por meio de uma escala Likert variando de 1 (nenhuma importância) a 5 (muito importante).

Os procedimentos para a coleta dos dados compreenderam a solicitação, no caso dos 
estudantes, de permissão nas IES para a aplicação do questionário presencialmente nas salas de aula e, no tocante aos profissionais, a solicitação foi feita nos Conselhos Regionais de Contabilidade selecionados, para que o instrumento de coleta de dados da pesquisa

\section{RESULTADOS E ANÁLISES}

\subsection{Aspectos descritivos}

Após a adoção de estratégia amostral compreensiva, este estudo conta com evidências brasileiras de 1.710 sujeitos: 941 profissionais e 769 estudantes, todos da área de Contabilidade. No caso dos profissionais, observa-se maior participação de homens (61\%). Quanto à idade, os profissionais (34\%) apresentam 41 anos ou mais, ou seja, quase dois terços da amostra é de profissionais com 40 anos ou menos. Praticamente metade (48\%) da amostra de profissionais apresenta pelo menos 10 anos de experiência profissional, sendo que a atividade modal (31\%) foi "contador, empregado de companhia privada." Sobre a educação superior, a grande maioria (85\%) vem de instituições de ensino privadas, com $45 \%$ da amostra portadores de diploma de bacharelado e $47 \%$ com certificados de especialização ou MBA. No caso dos estudantes da amostra, há participação equivalente de homens e mulheres. Há grande participação (76\%) de alunos de cursos noturnos; maioria (55\%) da amostra desenvolvendo seus estudos em escolas privadas e um total de $58 \%$ dos participantes trabalhando formalmente enquanto fazem seus cursos. Aproximadamente 63\% dos participantes declararam estudar semanalmente por 4 horas ou mais (além do período de aulas), sendo que as mulheres reportaram menos (61\%) que os homens (66\%). Essas evidências podem apoiar-se no processo de compreensão das dimensões socioeconômicas e culturais do sistema educacional e profissional analisado neste estudo, principalmente relacionado a áreas urbanas de alta densidade. fosse enviado aos contadores registrados nesses conselhos, via correio eletrônico. Após a aprovação da solicitação, foi enviada carta de apresentação dos pesquisadores, explicando os objetivos da pesquisa e contendo o link de acesso ao instrumento.

\subsection{Percepções de estudantes e profissionais}

No primeiro grupo de hipóteses selecionadas para análise neste estudo, todas apresentaram resultados estatisticamente significativos que apontam para maiores níveis de importância percebida pelos profissionais (quando comparados aos estudantes) nos quesitos conhecimento, habilidades e métodos de ensino-aprendizagem. A análise dos dados amostrais apresentou resultados $(t(1707)=-6,602$, sig. $=0,000$, direcional $)$ que suportam a hipótese de que profissionais $(\mathrm{M}=4,11$ e $\mathrm{DP}=0,57)$ percebem maior importância dos conhecimentos $\left(\mathrm{H}_{1}\right)$ quando comparados aos estudantes $(\mathrm{M}=3,94$ e $\mathrm{DP}=0,48)$. De igual modo, a análise dos dados amostrais permite suportar $(t(1707)=$ $-8,922$, sig. $=0,000$, direcional) a hipótese de que profissionais $(\mathrm{M}=4,41$ e $\mathrm{DP}=0,45)$ percebem maior importância das habilidades $\left(\mathrm{H}_{2}\right)$ quando comparados aos estudantes $(M=4,20$ e $D P=0,53)$. Por fim, dados amostrais suportam $(t(1707)=-9,093$, sig. $=$ 0,000, direcional) a hipótese de que profissionais $(\mathrm{M}=4,39$ e $\mathrm{DP}=0,52)$ percebem maior importância dos métodos de ensinoaprendizagem $\left(\mathrm{H}_{3}\right)$ quando comparados aos estudantes $(M=4,15$ e $\mathrm{DP}=0,61)$.

\subsection{Testes por categorias essenciais sobre as percepções dos estudantes}

No segundo grupo de hipóteses, que relaciona a percepção de importância dos estudantes e as categorias como gênero, vínculo empregatício e período do curso, evidências 
intrigantes foram descobertas. Analisandose a hipótese $\mathrm{H}_{4}$ (há diferenças significativas entre as percepções de importância dos estudantes quanto aos conhecimentos, habilidades e métodos de ensino-aprendizagem em função do gênero), descobriu-se que todas as variáveis de percepção de importância (conhecimento, habilidades, métodos e geral) apresentaram diferenças significativas em termos de gênero (Tabela 1). Respostas das estudantes foram sempre superiores. Assim, aceita-se a hipótese $\mathrm{H}_{4}$.

Tabela 1 Percepção de Importância: Comparação por gênero (estudantes)

\begin{tabular}{l|l|l|l}
\multicolumn{1}{c|}{ Tópico } & \multicolumn{1}{|c|}{$\begin{array}{c}\text { Homens }(\boldsymbol{n = 3 8 9}) \\
\boldsymbol{M}(\boldsymbol{D P})\end{array}$} & \multicolumn{1}{c}{$\begin{array}{c}\text { Mulheres }(\boldsymbol{n}=\mathbf{3 7 9}) \\
\boldsymbol{M}(\boldsymbol{D P})\end{array}$} & \multicolumn{1}{c}{ Comparação de médias } \\
\hline Conhecimento & $3,88(0,52)$ & $3,99(0,44)$ & $t(766)=-3,027(0,003) *$ \\
\hline Habilidades & $4,13(0,57)$ & $4,27(0,48)$ & $t(766)=-3,787(0,000) *$ \\
\hline Métodos & $4,06(0,64)$ & $4,24(0,55)$ & $t(765)=-4,255(0,000) *$ \\
\hline Geral & $4,01(0,48)$ & $4,14(0,40)$ & $t(766)=-4,161(0,000) *$ \\
\hline
\end{tabular}

Obs.: $M$ (média), $D P$ (desvio padrão).

* Diferenças significativas no nível alfa de 0,05.

Os resultados da análise da hipótese $\mathrm{H}_{5}$ (há diferenças significativas entre as percepções de importância dos estudantes quanto aos conhecimentos, habilidades e métodos de ensino-aprendizagem em função de vínculo empregatício) não geraram evidencias suficientes para suportar essa hipótese. Para nenhuma das três variáveis (conhecimento, habilidades e método), os resultados dos estudantes com vinculo empregatício foram diferentes daqueles sem o referido vínculo.

Igualmente, ao analisar os dados com foco na hipótese $\mathrm{H}_{6}$ (há diferenças significativas entre as percepções de importância dos estudantes quanto aos conhecimentos, habilidades e métodos de ensino-aprendizagem em função do período do curso), os resultados não mostram diferenças significativas. Para nenhuma das três variáveis (conhecimento, habilidades e método), os resultados dos es- tudantes do período noturno foram diferentes daqueles do período diurno.

\subsection{Testes por categorias essenciais sobre as percepções dos profissionais}

O último grupo de hipóteses, que relaciona a percepção de importância dos profissionais e as categorias como gênero, tempo de exercício da profissão e titulação, foi analisado e gerou resultados não menos intrigantes. Inicialmente, analisando-se a hipótese $\mathrm{H}_{7}$ (há diferenças significativas entre as percepções de importância dos profissionais quanto aos conhecimentos, habilidades e métodos de ensino-aprendizagem em função do gênero), descobriu-se que, em todas as variáveis, as percepções de importância das mulheres foram superiores às dos homens (Tabela 2). Assim a hipótese $\mathrm{H}_{7}$ foi aceita.

Tabela 2 Percepção de Importância: Comparação por gênero (profissionais)

\begin{tabular}{|c|c|c|c|}
\hline Tópico & $\begin{array}{c}\text { Homens }(n=572) \\
M(D P)\end{array}$ & $\begin{array}{c}\text { Mulheres }(n=369) \\
M(D P)\end{array}$ & Comparação de médias \\
\hline Conhecimento & $4,07(0,57)$ & $4,16(0,55)$ & $t(939)=-2,587(0,010)^{*}$ \\
\hline Habilidades & $4,38(0,46)$ & $4,45(0,44)$ & $t(939)=-2,387(0,017) *$ \\
\hline Métodos & $4,35(0,53)$ & $4,46(0,49)$ & $t(939)=-3,099(0,002) *$ \\
\hline Geral & $4,24(0,46)$ & $4,33(0,45)$ & $t(939)=-2,902(0,004) *$ \\
\hline
\end{tabular}

Obs.: $M$ (média), DP (desvio padrão).

* Diferenças significativas no nível alfa de 0,05. 
Foram testados os dados da amostra de profissionais para averiguar se há suporte para a hipótese $\mathrm{H}_{8}$ (há diferenças significativas entre as percepções de importância dos profissionais quanto aos conhecimentos, habilidades e métodos de ensino-aprendizagem em função do tempo de exercício da profissão). Os resultados da ANOVA apontam para inexistência de diferenças significativas, nas variáveis analisadas, em função do tempo de experiência profissional. A hipótese $\mathrm{H}_{8}$ foi rejeitada com base nos resultados de percepção de importância de conhecimento $(F(940)=$ $0,785$, sig. $=0,457)$, habilidades $(F(940)=$ $0,426$, sig. $=0,653)$, método $(F(940)=0,096$, sig. $=0,908)$, e percepção geral $(F(940)=$ 0,390, sig. $=0,677$ ).

Por fim, foram explorados os dados da amostra para teste da hipótese $\mathrm{H}_{9}$ (há diferenças significativas entre as percepções de importância dos profissionais quanto aos conhecimentos, habilidades e métodos de ensino-aprendizagem em função da titulação). Nesse caso, com base nos resultados da ANOVA, foi detectada diferença significativa na percepção de importância de habilidades $(F(940)=3,264$, sig. $=0,021)$. Todas as outras variáveis não apresentaram diferenças significativas em razão da titulação dos profissionais: conhecimentos $(F(940)=0,692$, sig. $=$ 0,557), método $(F(940)=1,048$, sig. $=0,370) \mathrm{e}$ percepção geral $(F(940)=1,191$, sig. $=0,312)$. Desse modo, os resultados suportam a hipótese $\mathrm{H}_{9}$ em questão (em razão da diferença obtida em habilidades).

\subsection{Comparações com outros países}

A julgar pela presença das economias do Brasil, China e EUA no contexto global atual e das tendências profissionais internacionais para a área de Contabilidade, a comparação desses resultados com o que a literatura apresenta sobre esses países é muito apropriada. Entretanto, é importante destacar duas condições para essa comparação: tamanho amostral e momento da coleta de dados. A seguir, apresentam-se análises comparativas para os profissionais (envolvendo Brasil, China e EUA) e os estudantes (envolvendo Brasil e China). Comparativos com os EUA são apresentados com base no estudo de Albrecht e Sack (2000) e com a China com base no estudo de Lin, Xiong e Liu (2005).

Os resultados dos três países selecionados mostram que os escores dos profissionais brasileiros são sempre maiores para as três dimensões analisadas (conhecimentos, habilidades e métodos). Os menores escores para Brasil e EUA são em conhecimentos $(4,11$ e 2,95 , respectivamente), enquanto para a China foi habilidades $(3,38)$. Maiores níveis de importância percebida dentre os profissionais brasileiros podem estar ligados à interferência direta do governo e órgãos reguladores, focando o processo de harmonização contábil internacional. O maior escore para os profissionais brasileiros relaciona-se com as habilidades, enquanto nos EUA e China é relacionado com métodos $(3,69$ e 3,59, respectivamente).

O mais alto escore para conhecimento foi no item tributária (4.83) para os brasileiros, e contabilidade financeira para China e EUA (4,66 e 3,57, respectivamente). Isso tem relação com a realidade das organizações no Brasil, convivendo com altas cargas tributárias e a predominância da contabilidade fiscal sobre a financeira. Ao focar as habilidades percebidas como mais importantes dentre os profissionais brasileiros, desponta tomada de decisões $(4,81)$, os chineses apontaram técnicas computacionais $(3,86)$, já nos EUA a indicação foi para a comunicação escrita $(4,32)$. Sobre métodos instrucionais, os brasileiros e os chineses apontaram análise de informações (4,68 e 4,26, respectivamente), já nos EUA foi destacado o método com trabalhos escritos $(4,25)$.

A análise dos resultados dos estudantes, comparativamente entre Brasil e China, apresenta pontos interessantes para esta pesquisa. Os estudantes brasileiros, de forma geral, atri- 
buem maior importância às três dimensões analisadas (conhecimentos, habilidades e métodos). Esse fenômeno pode ser parcialmente explicado pela forte presença do trabalho na vida dos estudantes brasileiros, o que os aproximaria da realidade do mercado de trabalho e correspondentes demandas profissionais.

Os dois itens de conhecimento com maiores escores dentre os estudantes brasileiros foram contabilidade tributária $(4,68)$ e contabilidade financeira $(4,70)$, enquanto os estudantes chineses reportaram contabilidade financeira $(4,71)$ e finanças $(4,55)$. Esse fato, também, pode estar relacionado com o momento e contexto empresarial brasileiro, destacando-se o papel fiscal da Contabilidade no Brasil, bem como o estágio de harmonização contábil internacional. Destaque-se que, ao serem analisadas as habilidades, os bra- sileiros apontaram como de maior relevância o pensamento crítico e analítico $(4,68)$ e a tomada de decisões $(4,57)$. Estes itens não foram elevados na percepção dos estudantes chineses, que identificaram maior importância para línguas estrangeiras $(4,22)$ e técnicas computacionais $(4,15)$. Sobre métodos instrucionais, estudantes brasileiros e chineses destacaram como mais importantes os que envolvem análises de informações (4,42 e 4,48 , respectivamente), sendo o segundo mais importante a motivação para os brasileiros $(4,38)$ e projetos envolvendo empresas, para os chineses $(4,31)$. É interessante destacar que para os estudantes chineses a percepção de importância de métodos instrucionais é a maior $(3,96)$ dentre as três analisadas. Para os estudantes brasileiros, a maior importância $(4,20)$ é dada a habilidades.

\section{CONCLUSÃO}

Evidências obtidas neste estudo, devidamente suportadas pela revisão da literatura, podem ser consideradas satisfatórias ao permitir a interpretação e compreensão sobre os conhecimentos, habilidades e métodos de ensino-aprendizagem considerados relevantes, segundo a percepção de estudantes e profissionais da Contabilidade no Brasil. Reconhecendo as limitações em termos de método e procedimentos amostrais, são apresentadas e discutidas conclusões e sugestões para futuras pesquisas, considerando-se que a questão de pesquisa foi respondida.

Quanto ao primeiro grupo de hipóteses $\left(\mathrm{H}_{1}, \mathrm{H}_{2}\right.$ e $\left.\mathrm{H}_{3}\right)$, observou-se que todas apresentaram resultados estatisticamente significativos, revelando que, para os profissionais, os conhecimentos, as habilidades e os métodos de ensino-aprendizagem são mais importantes do que o são para os estudantes. Pode-se observar, também, que tanto para os estudantes como para os profissionais, os conhecimentos têm menor importância se comparados às percepções em relação às habilidades e métodos de ensino-aprendizagem. Tal resultado significa que ambos (estudantes e profissionais) percebem maior relevância em desenvolver habilidades e explorar diferentes métodos de ensino-aprendizagem como caminho para impulsionar o seu desempenho profissional, o que constitui uma importante contribuição aos gestores dos cursos. A menor importância atribuída aos conhecimentos pode ser influência das especificidades relacionadas às características das Ciências Contábeis.

Os profissionais brasileiros atribuíram maior relevância às três variáveis (conhecimentos, habilidades e métodos de ensinoaprendizagem) quando comparados aos profissionais norte-americanos e chineses. Essa posição pode estar relacionada ao atual momento por que passa a Contabilidade no Brasil, com um maior nível de exigência sobre os profissionais a partir de 2010, em função do calendário de adoção das normas internacionais de Contabilidade. Além disso, chama a atenção o fato de o conhecimento sobre tri- 
butação ter sido considerado como relevante, indicando que os profissionais ainda não estão preparados para desconectar a área financeira da fiscal nesse atual contexto.

Ao se comparar a percepção de relevância atribuída por profissionais e por estudantes brasileiros, pode-se observar resultados similares, sendo que os profissionais apresentaram escores mais elevados em todas as três variáveis analisadas (conhecimentos, habilidades e métodos de ensino-aprendizagem). Isso pode sugerir que o mercado está exigindo muito mais do que os estudantes são capazes de perceber.

$\mathrm{O}$ segundo grupo de hipóteses $\left(\mathrm{H}_{4}, \mathrm{H}_{5} \mathrm{e}\right.$ $\left.\mathrm{H}_{6}\right)$ preconizava haver diferenças significativas entre as percepções de importância dos estudantes quanto aos conhecimentos, habilidades e métodos de ensino-aprendizagem em função do gênero, vínculo empregatício e turno do curso (diurno ou noturno). Foram observadas diferenças significativas em termos de gênero, com respostas superiores das estudantes. Não se observaram diferenças significativas na percepção de importância dos estudantes quanto às três categorias em função de vínculo empregatício e turno em que estão matriculados no curso (diurno ou noturno).

Os testes por categorias essenciais sobre as percepções de importância dos profissionais em função do gênero, tempo de exercício da profissão e titulação $\left(\mathrm{H}_{7}, \mathrm{H}_{8}\right.$ e $\left.\mathrm{H}_{9}\right)$, revelaram, quanto ao gênero, que, em todas as três variáveis, as percepções das mulheres foram superiores às dos homens. Os resultados revelaram não existir diferenças significativas nas variáveis analisadas, levando em conta o tempo de experiência dos profissionais no mercado de trabalho. No que tange à titulação dos profissionais, os resultados da ANOVA revelaram diferença significativa quanto à percepção de importância das habilidades, não ocorrendo o mesmo em relação aos conhecimentos e métodos de ensino-aprendizagem.

Constatou-se, ainda, que os escores decor- rentes das percepções dos profissionais foram superiores aos dos estudantes nas três variáveis. Os profissionais podem ter respondido aos questionários muito mais baseados na necessidade de adaptação ao novo mercado do que propriamente em função do currículo cursado, pois aqueles formados com base nas novas Diretrizes Curriculares, concebidas dentro de uma lógica que privilegia o desenvolvimento de conhecimentos, habilidades e competências, ainda não estão no mercado, uma vez que elas foram implantadas somente a partir de 2007. Outro elemento a ser considerado diz respeito a uma possível autosseleção da amostra, ou seja, os profissionais que responderam aos questionários muito possivelmente estão atuando em empresas que já demandam novos conhecimentos. De qualquer forma, chama a atenção o fato de os escores de ambos coletivos se apresentarem bem acima do ponto central da escala, diferentemente do que foi observado nos estudos realizados com profissionais e estudantes norte-americanos e chineses por Albrecht $\mathrm{e}$ Sack (2000) e Lin Xiong Liu (2005), respectivamente. Esses altos escores podem caracterizar o fenômeno conhecido como inflação das respostas e, em consequência, constituir uma limitação da pesquisa.

Os maiores escores decorrentes das percepções dos estudantes brasileiros ante aos norte-americanos e chineses nas três dimensões analisadas, podem estar relacionados com o fato de a maioria dos estudantes brasileiros já se encontrar atuando no mercado de trabalho, sendo favorecidos pela oferta de cursos noturnos, de um lado, mas, de outro, por serem impelidos a trabalhar em função do contexto socioeconômico do país, o que lhes proporciona uma visão mais nítida sobre a realidade do mercado e das demandas profissionais decorrentes, mas lhes tira tempo de dedicação aos estudos.

Outro elemento que deve ser levado em consideração no contexto de estudos dessa natureza, diz respeito às expectativas dos jo- 
vens sobre trabalho e profissão. Eles passam a demandar preparação para atuar profissionalmente dentro do país ou no exterior, em consonância com as demandas do próprio mercado. Considerados como pertencentes à geração Y, estão habituados a viver em ação e desenvolver múltiplas tarefas simultaneamente, valendo-se dos mais modernos meios de comunicação, o que desafia os gestores dos cursos a contemplar nos currículos elementos que possam atender aos seus anseios.

Destaque-se que a análise comparativa dos escores dos estudantes e dos profissionais brasileiros com os da China e EUA não considera o cenário socioeconômico e cultural desses países. Vale ressaltar, ainda, que os elevados escores apontados pelos respondentes brasileiros merecem atenção por parte dos gestores das IES, levando em conta a intensidade das mudanças de perfil dos jovens estudantes e a velocidade das alterações do mercado profissional. Assim, com base neste estudo, recomenda-se que os gestores dos programas dos cursos de Ciências Contábeis se mantenham vigilantes quanto à atualização e adequação dos conhecimentos, habilidades e métodos instrucionais necessários aos estudantes e, consequentemente, futuros profissionais, com o objetivo de promover o reconhecimento internacional dos profissionais contadores brasileiros.

Considerando: (a) resultados das hipó- teses (escores mais elevados dos estudantes e profissionais brasileiros); (b) participação mais intensa no mercado de trabalho por parte dos estudantes brasileiros (inclusive o tipo de trabalho realizado); (c) maior dinâmica do mercado de trabalho, notadamente o global, com demandas mais essenciais e menos operacionais e (d) movimento de estabelecimento de processos para credenciamento profissional em termos globais (e.g., ACCA, AICPA), observa-se que existem aberturas para experimentos com novos modelos de curso, atração de novos perfis de estudantes, readequação de carga horária dedicada a disciplinas de formação geral, reflexão sobre níveis de dedicação ao curso por parte dos docentes e discentes, maior exposição a métodos de ensino que privilegiem o desenvolvimento do raciocínio crítico e as habilidades de comunicação e maior exposição às novas demandas do futuro mercado de trabalho global e maior exposição a métodos de ensino que privilegiem o desenvolvimento do raciocínio crítico e as habilidades de comunicação.

Sugere-se que futuros estudos sejam conduzidos para analisar as razões pelas quais os estudantes e profissionais brasileiros estão percebendo como relevantes o desenvolvimento de habilidades e o uso de diferentes métodos de ensino e aprendizagem para impulsionar o seu desempenho profissional.

\section{Referências}

\section{ACCOUNTING EDUCATION CHANGE}

COMMISSION. Objective of education for accountants: Position statement number one. Issue in Accounting Education, v. 5, p. 307-312, 1990.

AECC - Accounting Education Change Commission. The Accounting Education Change Commission: its history and impact, 1999. Disponível em: < http://aaahq. org/aecc/history/cover.htm> Acesso em: 21 dez. 2010. ALBRECHT, W. S.; SACK, R. J. Accounting Education: Charting the Course through a Perilous Future. Accounting Education Series, v. 16. American Accounting Association, 2000.

AMERICAN INSTITUTE OF CERTIFIED PUBLIC ACCOUNTANTS (AICPA). CPA vision project identifies top five issues for the profession. The CPA Letter, v. 1, n. 12, 1998.
AMERICAN INSTITUTE OF CERTIFIED PUBLIC ACCOUNTANTS. Mapping of the AICPA Core Competency Framework to the skills tested on the CPA exam. New York: AICPA. 2010. Disponível em: http:// www.aicpa.org/InterestAreas/AccountingEducation/ Resources. Acesso em: $21 \mathrm{dez} .2010$. ANDERSON, L. W.; KRATHWOHL, D. R.; AIRASIAN, P. W.; CRUIKSHANK, K. A.; MAYER, R. E.; PINTRICH, P. R.; RATHS, J.; WITTROCK, M. C. A taxonomy for learning, teaching, and assessing: a revision of Bloom's Taxonomy of Educational Objectives. Longman: New York, 2001.

ARQUERO, et al. Accounting students and communication apprehension: a study of Spanish and UK students. European Accounting Review, v.16, n.2, p. 299-322, July 2007.

AUSUBEL, D. P. Aquisição e retenção de conhecimentos: uma perspectiva cognitiva. Lisboa: Plátano Edições 
Técnicas, 2003.

BLOOM, B. S. Taxonomy of educational objectives: The classification of educational goals, by a committee of college and university examiners. Handbook I. Cognitive Domain. New York: Longmans, Green.1956.

BOLT-LEE, C.; FOSTER, S. D. The Core Competence Framework: a new element in the accounting call for accounting education change in the United States. Accounting Education, v.12, n.1, p. 33-47, Mar. 2003. BRASIL. Resolução CNE/ CES no. 10, de 16 de dezembro de 2004. Institui as Diretrizes Nacionais Curriculares para o Curso de Graduação em Ciências Contábeis, bacharelado, e dá outras providências. In: CONSELHO NACIONAL DE EDUCAÇÃO - CÂMARA DE EDUDAÇÃO SUPERIOR. Legislação Republicana Brasileira. Brasília, 2004. Disponível em: <http://portal mec.gov.br/cne/arquivos/pdf/rces10_04.pdf >. Acesso em: 20 out. 2010.

BURNETT, S. The future of accounting education: A regional perspective. Journal of Education of Business, v. 78, n. 3, p. 129-136, 2003.

CARR, S.; CHUA, F.; PERERA, H.. University accounting curricula: perceptions of alumni group. Accounting Education, v.13, n.1, p. 51-67, Mar. 2004. CRESWELL, J. W. Research design: Qualitative, quantitative, and mixed methods approaches, $2 \mathrm{ed}$. Thousand Oaks, CA: Sage, 2003.

FRANCISCO, B., KELLY, A. Beyond Albrecht and Sack: A comparison of accounting professionals and college students. Working Paper, 2002.

GALL, M. D.; GALL, J. P.; BORG, W. R. Educational research: an introduction. 7 ed. Boston: Allyn and Bacon, 2003.

HASSAL, T. et al. The vocational skills gap for management accountants: the stakeholders' perspectives. Innovations in Education and Teaching International, v.40, n.1 , p. 78-88, Feb. 2003.

HOWIESON, B.. Accounting practice in the new millennium: is accounting education ready to meet the challenge? The British Accounting Review, n.35, p. 69-103, 2003.

\section{INTERNATIONAL FEDERATION OF}

ACCOUNTANTS. Handbook of International Education Pronouncements 2010 Edition. New York, 2010.

Disponível em: http://www.ifac.org. Acesso em: 27 dez.2010

\section{INTERNATIONAL FEDERATION OF}

ACCOUNTANTS. IAESB 2010-2012 Strategy and Work Plan. New York, 2010a. Disponível em http://www.ifac. org/sites/default/files/publications/files/iaesb-20102012-strategy-an.pdf. Acesso em 28 de out. 2011.

KRATHWOHL, D. R., BLOOM, B. S., MASIA, B. B.

Taxonomy of educational objectives: The classification of educational goals. Handbook II, Affective Domain. New York: Longmans, Green.1964.

LIN, Z. J., DENG, S. Educating accounting in China: Current experience and future prospects.

The International Journal of Accounting, v. 27, n. 2, p. 164-173, 1991.

LIN, Z. J; XIONG, X.; LIU, M. Knowledge base and skill development in accounting education: evidence from China.
Journal Accounting Education, n. 23, p. 149-169, 2005. MARTINS, G. A.; THEÓPHILO, C. R. Metodologia da investigação científica para ciências sociais aplicadas, 2 ed. São Paulo: Atlas, 2009.

MARZANO, R. J. Designing a new taxonomy of educational objectives. Thousand Oaks, CA: Corwin Press, 2000.

MCCHLERY, S. ;PAISEY, C. Quality in professional accounting education provision in the UK - the CIMA experience. Accounting Education Taylor and Francis Journals, v. 12, n. 2, p. 197-225, 2003.

MOHAMED, E. K.A.; LASHINE, S. H. Accounting Knowledge and Skills and the Challenges of a Global Business Environment. 2003. Managerial Finance, v. 29, n. 7, p. 3-16, 2003.

MORGAN, G. J. Communication skills required by accounting graduates: practitioner and academic perceptions. Accounting Education, v.6, n.2, p. 93-107, June 1997.

NEEDLES JR, B. E.;CASCINI, K.; KRYLOVA, T.;MOUSTAFA, M. Strategy for Implementation of IFAC International Education Guideline No. 9: Prequalification Education, Tests of Professional Competence and Practical Experience of Professional Accountants: A Task Force Report of the International Association for Accounting Education and Research (IAAER). Journal of International Financial Management \& Accounting, v. 12, n. 3, p. 317-353, 2001.

NELSON, I. T.; BAILEY, J. A.; NELSON, T.. Changing accounting education with purpose: market-based strategic planning for departments of accounting. Issues in Accounting Education, v.13, n.2, p. 301-326, May 1998. PALMER, K. N.; ZIENGENFUSS, D. E.; PINSKER, R. E. International knowledge, skills, and abilities of auditors/ accountants: Evidence from recent competency studies. Managerial Auditing Journal, v. 19, n. 7, p. 889-896, 2004. PORTER, B. A.; CARR, S. Form the strategic plan to practical realities: developing and implementing a zero-based accounting curriculum. Issues in Accounting Education, v.14, n.4, p. 565-588, Nov. 1999.

SAMPIERI, R. H.; COLLADO, C. F.; LUCIO, P. B.

Metodologia de pesquisa. Tradução F. C. Murad, M. Kassner, S. C. D. Ladeira. 3 ed. São Paulo: McGraw-Hill, 2006. SELLTIZ, C.; WRIGHTSMAN, L. S.; COOK, S. W. Métodos de pesquisa nas relações sociais. Tradução: M.M.H. d'Oliveira, M.M.del Rey. 2. ed. São Paulo: EPU, 1987, vol. 1.

SELLTIZ, C.; WRIGHTSMAN, L. S.; COOK, S. W. Métodos de pesquisa nas relações sociais. Tradução: M.M.H. d’Oliveira, M.M.del Rey. 2. ed. São Paulo: EPU, 1987a, vol. 3.

SIEGEL, G.; KULESZA, C.S. The coming changes in management accounting education. Management Accounting Education, v. 77, p. 43-47, Jan. 1996. SMYTHE, M.J., NIKOLAI, L.A.A thematic analysis of oral communication concerns implications for curriculum design. Journal of Accounting Education, v. 20, p. 163-181, 2002.

TANG, Y. The recent accounting development and internationalization of accounting education in China. Issues in Accounting Education, v. 12, n. 1, p 219-227, 1997. 